\title{
POBLACIÓN FLOTANTE: TIPOLOGÍA DE VISITANTES EN TIJUANA*
}

\author{
Por \\ Nora L. Bringas Rábago \\ Ofelia Woo Morales**
}

\begin{abstract}
RESUMEN
Desde los inicios del presente siglo, el desarrollo de Tijuana ha sido marcado por el turismo nacional y extranjero. El objetivo de este trabajo es establecer una tipología de los visitantes que llegan a esta ciudad, a partir de los servicios que demandan, enfocando la atención en los turistas extranjeros y los migrantes en sus diferentes modalidades.

Se hará referencia específica a los migrantes que han llegado a esta frontera con la esperanza de emigrar hacia Estados Unidos, y que se ven en la necesidad de permanecer en la ciudad y hacer uso de diversos servicios, principalmente hospedaje y alimentación.
\end{abstract}

\begin{abstract}
Since the beginning of this century the development of Tijuana has been singularized by the national and international tourism.

The main idea of this article is to establish the types of visitors who arrive to this city, derived from the variety of services they demand, focusing our attention on the foreign tourists and the migrants in their different modalities.

Special attention will be given to the migrants who have arrived to this frontier hoping to migrate to the United States, and who find themselves in the need to stay in the city and use a great variety of services, such as food and lodging.
\end{abstract}

\section{INTRODUCCIÓN $\mathbf{N}^{1}$}

El turismo y la migración son dos procesos sociales que a pesar de realizarse por motivos y lógicas diferentes tienen en común la movilidad de personas.

Desde los albores del presente siglo, el turismo ha marcado el desarrollo de Tijuana debido a que es una de sus principales actividades económicas, mientras que el proceso migratorio ha sido determinante en su poblamiento.

* Este documento fue presentado en "El Coloquio sobre políticas de población en México" realizado en El Colegio de la Frontera Norte en Tijuana los días 3 y 4 de octubre de 1991.

** Investigadoras del Colegio de la Frontera Norte.

1 Agradecemos los valiosos comentarios y sugerencias de Rodolfo Corona, Manuel Valenzuela y Gabriel Estrella. 
A Tijuana llegan diariamente una gama variada de población flotante que se desplazan en la ciudad por diferentes motivos; en esta categoría están comprendidos: turistas nacionales y extranjeros, migrantes en sus diferentes modalidades y aquéllos que sólo vienen a realizar algún negocio. Independientemente de sus propósitos, todos ellos hacen uso de servicios y su estancia en la ciudad (temporal, no definitiva) repercute directamente en la economía de la misma.

Consideramos necesario diferenciar a la población que demanda diferentes tipos de servicios, porque esto nos permite conocer los cambios socioeconómicos y culturales que se pueden presentar en nuestra sociedad, asi como cubrir y mejorar los servicios que esta población requiere.

En este trabajo haremos referencia específicamente a los migrantes "indocumentados", quienes han llegado a esta frontera con la esperanza de emigrar hacia los Estados Unidos, y se ven en la necesidad de permanecer en la ciudad y hacer uso de diversos servicios, principalmente hospedaje y alimentación.

El objetivo del presente trabajo es establecer una tipología de los visitantes que llegan a Tijuana a partir del uso y la calidad de los servicios que demandan en la orientación de la infraestructura al interior de la ciudad, enfocando nuestra atención en los turistas extranjeros y los migrantes internacionales o "visitantes itinerantes". Asimismo se pretende hacer una estimación inicial de la aportación económica de esta parte de la población flotante en la ciudad de Tijuana. ${ }^{3}$

El documento consta de cinco secciones. En la primera se hace referencia a la importancia que el turismo y la migración han tenido para el desarrollo de Tijuana, tanto en el aspecto económico, como en su crecimiento poblacional. En la segunda se define a esta población flotante y los servicios que demandan dentro de los rubros de hoteles, restaurantes y transporte aéreo. En la tercera sección se presenta una tipología de los visitantes. En la cuarta se identifica la orientación y ubicación de los servicios; y, por último, en la quinta sección se señala la importancia económica que el turismo y la migración tienen para la ciudad de Tijuana.

\footnotetext{
2 No pretendemos señalar (o sugerir) que el migrante indocumentado es un turista, ya que los motivos de su estancia no se refieren a diversión o paseo, sino que dependen del éxito o fracaso de pasar hacia Estados Únidos en "el primer intento de cruce".

En el presente documento se pante del entendido de que la población flotante es aquélla que llega a la ciudad y permanece en ésta por periodos cortos. Dentro de esta población se considera, de acuerdo con la Encuesta demográfica de Baja California de 1986, a los no residentes, temporalmente presentes (véase definición pág. 69 y las características y variables que la definen en la pág. 34).
} 


\section{ANTECEDENTES HISTÓRICOS DE LA ACTIVIDAD TURÍSTICA Y LA MIGRACIÓN EN TIJUANA}

En este apartado se presentará una reseña histórica de los principales sucesos económicos, políticos y sociales que ejercieron una marcada influencia sobre el desarrollo de Tijuana, haciendo énfasis en el turismo y la migración, los cuales se manifiestan en la movilidad temporal o permanente de personas de ambos lados de la frontera: los turistas del norte y los migrantes del sur.

Algunos estudios realizados sobre la dinámica poblacional de Baja California indican que este estado se ha caracterizado por la confluencia de diferentes tipos de movimientos poblacionales, entre los que destacan la migración interna (definitiva), la interestatal y la internacional (Estrella, 1987; Corona, 1986). De acuerdo con la información censal, Tijuana ha sido tradicionalmente un importante imán de estos movimientos. En 1960 el $65.4 \%$ de la población tijuanense no era originaria de Baja California y sólo el 34.6\% había nacido en este municipio; sin embargo, para 1980 la situación cambió, pues la población nativa representaba el $46 \%$ de su población total (Mungaray, 1985: 203).

Tijuana ha sido un importante receptor de personas que por distintos motivos y en temporadas diferentes la visitan (recreación, turismo, o negocios); encontrándose entre estos visitantes a la población anglosajona, mexicoamericanos y asiáticos y, principalmente, la población mexicana procedente del interior del país.

\section{Origen y desarrollo de la actividad turística y la migración en Tijuana}

Desde épocas anteriores a la apertura de vías de comunicación y transporte ${ }^{4}$ que integraron al estado de Baja California con el resto del país, Tijuana estuvo sujeta a los vaivenes de la economía estadounidense, los cuales marcaron e influyeron de manera importante en su desarrollo y poblamiento.

A inicios del presente siglo, Tijuana era un pequeño poblado que contaba con 242 habitantes y experimentaba un incipiente desarrollo en la dotación de servicios públicos. En 1908 se promovieron algunos atractivos turísticos, tales como las carreras de galgos, corridas de toros $\mathrm{y}$ juegos de azar, que marcaron toda una época en Tijuana (Piñera, et al., 1985:67).

4 Fue hasta la década de los cuarenta cuando Baja Califomia se empezó a integrar al resto del país por la construcción de la carretera y la extensión del ferrocarril. 
Para 1910 Tijuana ya contaba con 733 habitantes y era un asentamiento rural rodeado de ranchos ganaderos (Pinera, et al., 1985:65-68). Hasta entonces, la economía tijuanense se basaba en las actividades primarias; sin embargo, en 1911 se da un giro con el inicio de la actividad turística, generándose una fuerte dependencia (en lo económico, político, social, cultural y turístico) de California y en particular con San Diego.

Simultáneamente a la bonanza económica que San Diego experimentaba durante la primera década de este siglo, Estados Unidos fue sacudido por un sentimiento moralista que se extendió rápidamente por todo su territorio; de tal suerte que en 1911 se prohibieron las cantinas y las apuestas de caballos; como resultado de este vedamiento Tijuana se convirtió en el sitio adecuado para llevar a cabo actividades socialmente condenadas en la Unión Americana; lo que provocó que la ciudad alcanzara un mayor auge como receptora de grandes núcleos de visitantes (Acevedo, et al. 1985:93), generándose una fuerte relación entre las necesidades de diversión de los extranjeros y la proliferación en Tijuana de actividades consideradas ilícitas en Estados Unidos.

$\mathrm{Al}$ concluir la primera guerra mundial se presentaron grandes corrientes turísticas en Tijuana en el marco del sentimiento moralista estadounidense que volvió a cobrar fuerza a finales de 1919, logrando que el congreso aprobara la "Ley Volstead" o "Ley seca", misma que entró en vigor en 1920 y mediante la cual se prohibió la producción y venta de licor en la Unión Americana. Esta ley propició una reacción en cadena en Tijuana, pues nuevamente las cantinas, licorerías y toda clase de centros de "vicio" empezaron a expandirse por la ciudad (Acevedo, et al., 1985:98).

La década de los años veinte se puede considerar como la "época de oro" del turismo en Tijuana. El gobierno estadounidense tomó medidas para frenar las visitas de sus ciudadanos hacia esta ciudad, quienes venían principalmente atraídos por el hipódromo y el casino de Agua Caliente. Una de las disposiciones que para este fin tomó el gobierno estadounidense fue cerrar el paso fronterizo a las nueve de la noche. Esta medida tuvo efectos distintos a los esperados, ya que propició que muchos de los extranjeros se quedaran a pernoctar en la ciudad, lo que provocó un repunte en la hotelería tijuanense (Acevedo, et al., 1985:104-105).

La gran crisis económica que azotó a Estados Unidos en 1929 se reflejó en la baja productividad y cierre de empresas, lo que produjo el desempleo de trabajadores agrícolas mexicanos que retornaron a la zona fronteriza y de los cuales algunos se quedaron en Tijuana y fundaron la colonia Libertad (Bustamante, 1990).

Se dice que esta crisis no tuvo efectos inmediatos en Tijuana puesto que quienes asistian a los centros de diversión y juego pertenecian a clases 
acaudaladas y la ley seca atraía a una enorme corriente de población anglosajona (Piñera, et al., 1985:129). En 1930, Tijuana contaba con 12,181 habitantes (Corona, 1991:18) y su economía dependía, en gran parte, de los establecimientos de juego y de venta de bebidas alcohólicas.

La derogación de la "ley seca" en Estados Unidos, en 1933, y el cierre de los establecimientos de juego en 1935, se tradujeron en una disminución del turismo en Tijuana. Como una medida para contrarrestar los efectos negativos que provocó la derogación en la economía local —que se tradujeron en el cierre de establecimientos - como una forma de estímulo en ese mismo año se autorizaron los perímetros libres experimentales para Ensenada y Tijuana, la cual contaba para entonces con 14,154 habitantes y 200 comercios diversos. $^{5}$

En 1940 Tijuana tenía 24,233 habitantes, había duplicado su población con respecto a la década anterior (Corona, 1991) y nuevamente el turismo experimentó un repunte con la participación de Estados Unidos en la segunda guerra mundial, pues empezaron a llegar a esta ciudad miles de marinos de la base militar de San Diego, quienes llegaban en busca de diversión y bebidas embriagantes (Piñera, et al., 1985:138).

La migración internacional también contribuyó fuertemente al desarrollo poblacional de Tijuana, pues durante la lucha bélica Estados Unidos solicitó la incorporación temporal de trabajadores mexicanos a las labores de campo a través del llamado programa de braceros, iniciado en 1942.

La segunda guerra mundial fue un acontecimiento histórico que provocó grandes desplazamientos poblacionales; en Tijuana coincidían los turistas del norte y los migrantes del sur, procesos que generaron un acelerado crecimiento poblacional y un importante desarrollo económico.

Durante ese período llegaron a Tijuana miles de personas que pretendían cruzar la frontera para trabajar en el vecino país; muchos de ellos permanecían por largas temporadas en la ciudad, mientras que otros optaron por residir en Tijuana de forma permanente. La migración internacional se incrementó aún más a partir de la inauguración del ferrocarril Sonora-Baja California en 1948 (Piñera, et al., 1985:142; Kusel, s/f).

La migración de indocumentados hacia Estados Unidos se ha realizado desde inicios de este siglo hasta la fecha con diversos grados de intensidad; en algunos momentos motivada por razones políticas como ocurrió en la época de la revolución mexicana (1910-1917); y en otras por razones

5 A partir de entonces inició su despegue la actividad comercial pues se permitía la libre importación de artículos de primera necesidad y diversas mercancías. Muchos de los negocios de mexicanos que se encontraban en San Ysidro cambiaron su domicilio a Tijuana, lo que reactivó aún más esta actividad. Cfr. Pifiera et al., 1985: 133-134). 
económicas, como sucedió durante el programa bracero (1942-1964); y recientemente, con la ley Simpson-Rodino, que tuvo por objetivo frenar el flujo de nuevos migrantes, legalizando a quienes podían comprobar su estancia en Estados Unidos desde 1982 implementando medidas restrictivas para sancionar a quienes emplearan mano de obra indocumentada a partir de la fecha de aprobación de dicha ley, reforzando, con este fin, al Servicio de Inmigración y Naturalización.

En 1950 el municipio de Tijuana contaba con 69,999 habitantes que significaban el $29 \%$ del total estatal, y había registrado un crecimiento del 189\% con respecto a la década anterior. Para 1960 su población había crecido $(177,092)$ en $153 \%$ (Corona, 1991:18).

Durante el período de posguerra, la ciudad de Tijuana continuaba recibiendo grandes flujos de militares asentados en la base naval de San Diego, como consecuencia de la intervención de Estados Unidos en las guerras de Corea y de Vietnam; sin embargo, en términos relativos, esta actividad estaba perdiendo importancia.

Durante los años cincuenta el comercio y el turismo eran la base de la economía tijuanense, representando entre ambos más de la mitad de la población económicamente activa (PEA), distribuida de la siguiente manera: el $24.2 \%$ en la agricultura y el $23.8 \%$ en la industria; sin embargo, el sector terciario de la economía empezó a ganar terreno después de la segunda guerra mundial (Küsel, s/f:16), y para 1960 el 51.2\% de la PEA de Tijuana se localizaba en las actividades comerciales y de servicios (Mungaray, 1985:203).

Como consecuencia del crecimiento poblacional derivado del gran volumen de trabajadores deportados con la cancelación del programa Braceros en 1964, las ciudades fronterizas, principalmente Tijuana, se enfrentaron a un agudo problema en la dotación de servicios y generación de empleos.

Como una medida para atenuar estos problemas, en 1965 se creó el Programa de Industrialización Fronteriza (PIF), que tenía entre sus principales objetivos generar empleo y mejorar las condiciones de vida de la población fronteriza. Sin embargo, en la práctica, el segundo objetivo no se cumplió y la búsqueda de mejores opciones de vida es una de las razones por las que miles de nacionales continúan emigrando hacia Estados Unidos.

Con el tiempo, Tijuana se fue convirtiendo en una "ciudad de paso" para algunos migrantes, pues aquéllos que eran deportados de los Estados Unidos se quedaban en la ciudad para hacer otro intento de cruzar; otros permanecían y otros más regresaban a sus lugares de origen; así la deportación de los migrantes ha tenido histórica relevancia en el crecimiento de la ciudad. 
En la actualidad, este tipo de deportaciones de decenas de migrantes ocurre diariamente; pero no es el objetivo de este trabajo profundizar sobre este tema.

A inicios de la década de los setenta Tijuana contaba con 368,951 habitantes, que representaba el $39 \%$ del total estatal; en esta década y en la siguiente se registra una fuerte composición urbana del municipio, pues el $99 \%$ de la población era urbana y sólo uno por ciento era rural; este rasgo se vio acentuado por el constante arribo de personas que buscaban empleo, alentados por la creación del PIF.

El sector agropecuario ocupaba sólo al $6.6 \%$ de la PEA, en tanto que el sector secundario o industrial empezó a ganar terreno y el comercio y los servicios se incrementaron, siendo la PEA de 33.6 y $59.8 \%$, respectivamente (Mungaray, 1985). La importancia del sector terciario se ilustra de manera clara cuando se observa que el total de cruces extranjeros que se registraron en Tijuana en 1973 fue de 14.4 millones, mismos que significaban el $71.6 \%$ del total estatal (Servicio de Inmigración y Naturalización de los Estados Unidos, 1973) y que en su mayoría demandaban servicios comerciales y turísticos.

En la década de los ochenta Tijuana contaba con una población de 478,956 habitantes. En esta década la ciudad experimentó cambios en su organización urbana y consolidó su estructura económica, perfilándose como una importante plaza financiera, comercial, industrial y de servicios orientados al turista.

Para 1980 la PEA se distribuía de la siguiente manera: $4.7 \%$ en el sector primario, $36.5 \%$ en el secundario y $58.8 \%$ en el secior terciario. En este último, el comercio y el turismo conformaban el $42.7 \%$ de la PEA del sector terciario (INEGI, 1980). Para 1988, Ia mayor concentración de la PEA se encontraba en el sector terciario, que representaba el $6 ? .4 \%$ de la misma; posteriormente se encontraba el sector secundario con el $27.6 \%$ y, finalmente, el primario con $7.1 \%{ }^{6}$

La baja representación estadística de la participación del turismo en la PEA está asociada con un subregistro, de su efecto en diversas ramas de actividad, pues la información oficial sólo considera las operaciones que se realizan en hoteles, restaurantes y bares, dejando de lado los empleos que el turismo genera en los rubros de construcción, transporte aéreo y terrestre, agencias de viajes, tiendas de artesanías y de importación y licorerías.

6 El comercio, con el 35.7, y el turismo, con el $9.3 \%$ significaban el $45 \%$ del sector terciario (CONEPO, 1989). 
Con la aprobación de la ley Simpson-Rodino en 1986, se suscitó una gran expectación sobre supuestas deportaciones masivas de migrantes indocumentados y sus efectos previsibles en ciudades fronterizas. Esta situación no se presentó; sin embargo, sí estimuló la incorporación de nuevos migrantes que suponian que con dicha disposición podrían trabajar en Estados Unidos.

En la actualidad, la composición de la población flotante que llega a Tijuana se ha diversificado, además de los turistas anglosajones es necesario considerar la incorporación de los estadounidenses de ascendencia mexicana, los visitantes nacionales que vienen por negocios, los migrantes temporales y los legalizados a través de la Simpson-Rodino, to que diferencia a esta población es el motivo que subyace a su desplazamiento; en algunos casos se origina por trabajo y en otros por diversión, lo que determina las actividades y los servicios que se utilizan en la ciudad durante su estancia.

Históricamente, tanto la actividad turística como el fenómeno de la migración han mantenido un comportamiento cíclico, que depende de los períodos de auge y recesión de la economía estadounidense. Se puede señalar que los momentos de alta afluencia de turistas extranjeros a Tijuana han estado asociados con sucesos bélicos y disposiciones restrictivas de Estados Unidos sobre la diversión; mientras que los flujos migratorios y las políticas de migración están ligadas a las necesidades de mano de obra en el vecino pais, y a la búsqueda de mejores opciones de vida de los connacionales, como consecuencia del desempleo existente en el país derivado de la crisis económica.

\section{LA POBLACIÓN FLOTANTE Y LA OFERTA DE SERVICIOS}

Para dar atención tanto a la población nacional como extranjera, la ciudad cuenta con una planta de servicios compuesta por hoteles, restaurantes, bares, discotecas, agencias de viajes, arrendadoras de autos, una central de autobuses foráncos, un aeropuerto internacional, comercios y

\footnotetext{
7 Tijuana se ha convertido en las últimas décadas en la principal receptora no sólo de los migrantes indocumentados que emigran cada año hacia Estados Unidos, sino de una población que se está incorporando a este proceso migratorio; con respecto a esto último estamos hablando de una población que cruza por primera vez hacia Estados Unidos, de acuerdo con la información obtenida del proyecto Carín Zapata, aproximadamente el 50\% de la población que fue entrevistada en Tijuana es la primera vez que emigra a Estados Unidos. 8 Varios estudiosos del terna han serialado la relación que existe entre la recesión económica en Estados Unidos y los cambios en la política migratoria para controlar el flujo migratorio. (Véase Jonge Bustamante y Wayne Cornelius, 1989).
} 
artesanías, todo ello orientado a satisfacer las necesidades que demanda principalmente el turismo anglosajón. ${ }^{9}$

Por su situación estratégica frente al estado más rico de la Unión Americana (California) y, actualmente, por su incorporación a la Cuenca del Pacífico, Tijuana tiene una doble función; por una parte es la principal puerta de entrada de los extranjeros a México y al mismo tiempo es la principal ciudad de cruce de migrantes indocumentados a Estados Unidos.

Tijuana es un importante núcleo receptor de población flotante. Principalmente en la actividad de turismo resulta desolador constatar la ausencia de estadísticas confiables acerca de las corrientes turísticas que la visitan y su aportación a la economía local. Hasta la fecha no es posible hablar con certeza de la magnitud del fenómeno turístico, pese a su evidente importancia en la vida económica de la región. Para tener una idea de la afluencia de visitantes extranjeros a la ciudad utilizaremos las estadísticas existentes sobre cruces fronterizos, haciendo la aclaración de que no los estamos considerando como turistas, ${ }^{10} \mathrm{ni}$ suponemos que quienes fueron registrados en estos cruces permanecieron en Tijuana, aunque consideramos que una parte importante sí lo hizo. En el caso del turismo nacional, nos encontramos con problemas similares de captación; por ello, para detectarlos, haremos uso de las estadísticas de ocupación hotelera.

\section{Afluencia de población extranjera y nacional en Tijuana}

Según el servicio de Naturalización e Inmigración de Estados Unidos (SIN), Tijuana es la ciudad que registra el mayor número de cruces de la frontera norte. Sin embargo, en comparación con 1989, año en que se registraron 27.7 millones de cruces extranjeros, en 1990 la afluencia hacia esta ciudad disminuyó considerablemente, llegando a 23.6 millones de cruces, posiblemente como consecuencia de la recesión económica en Estados Unidos, que viene acompañada de altas tasas de desempleo y disminución del salario real, además de su participación en la guerra del Golfo Pérsico. En 1990, julio fue el mes que presentó el más bajo registro en la captación de cruces (la disminución fue del orden del 31\%, comparada con

9 Es necesario señalar que en este punto sólo trataremos el aspecto de cobertura y no de çalidad de servicios.

10 Dado que en este rubro están englobados muchos de los mexicanos que viven en Tijuana y que cruzan a diario para trabajar en el vecino estado de California y hasta incluye a población mexicana que trae autos con placas extranjeras y se contabiliza como cruces distintos a los efectuados por una misma persona en un mismo día. 
el mismo mes del año anterior), aunque en términos anuales, el descenso fue de aproximadamente $15 \%$.

$\mathrm{Al}$ analizar la afluencia de la población nacional que visitó la ciudad, con base en la ocupación hotelera y el porcentaje de nacionales que hacen uso de este servicio, observamos que del total de la población que en 1989 hicieron uso de hoteles el $78.7 \%$ fueron nacionales y el resto extranjeros, lo que significa que hasta esta ciudad se desplazaron 1'095,900 connacionales, utilizando los distintos medios de transporte a su alcance. En 1989 se registró una disminución del $4.2 \%$ en la captación de población nacional en comparación con 1988. Se desconocen las causas del descenso, aunque suponemos que es consecuencia de la crisis económica por la que atraviesa México desde 1982 (véase cuadro 1)

CUADRO 1. Visitantes hospedados en hoteles de Tijuana (miles)*.

\begin{tabular}{lrrrrrr}
\hline \multicolumn{2}{c}{ Total } & \multicolumn{2}{c}{ Nacionales } & \multicolumn{2}{c}{ Extranjeros } \\
Año & Número & $\begin{array}{c}\text { Variación } \\
\text { anual (\%) }\end{array}$ & Número Porcentaje & Número Porcentaje \\
\hline & & & 863.0 & 80.8 & 205.0 & 19.2 \\
1985 & 1068.0 & & 1032.2 & 81.0 & 241.0 & 19.0 \\
1986 & 1273.2 & 19.2 & 105.5 & 79.0 & 280.4 & 21.0 \\
1987 & 1336.0 & 4.9 & 1055.5 & & & \\
1988 & 1403.9 & 5.1 & 1144.0 & 81.5 & 259.9 & 18.5 \\
1989 & 1391.8 & -0.9 & 1095.9 & 78.7 & 295.9 & 21.3 \\
\hline
\end{tabular}

FUENTE: Estadísticas básicas de la actividad turística, 1989. SECTUR.

* Incluye establecimientos de hospedaje con categoría: Clase especial, $1,2,3,4$ y 5 estrellas.

De acuerdo con la información de CONAPO, Tijuana es la ciudad fronteriza que registra la mayor proporción de población migrante que cruza hacia Estados Unidos; así, tenemos que el $48 \%$ del total de migrantes sin documentos que se introduce al vecino país utiliza a esta ciudad como punto de entrada hacia Estados Unidos (Bustamante, 1987).

Para conocer con mayor precisión el comportamiento del flujo migratorio hacia Estados Unidos se utilizará la información generada por el

\footnotetext{
11 Los datos de cruces son los que proporciona el Servicio de Inmigración y Naturalización y procesa la Secretaría de Turismo del Estado.
} 
proyecto "Cańon Zapata". ${ }^{12}$ Para efectos del presente trabajo sólo se hará referencia a la información de los migrantes indocumentados que cruzaron por la ciudad de Tijuana hacia Estados Unidos y que durante su estancia hacen uso de varios servicios, principalmente de alimentación y hospedaje.

Es importante resaltar que el flujo migratorio tiene un comportamiento estacional, donde la migración se incrementa en verano y desciende en invierno; esto puede ser atribuible a dos factores, por un lado, es resultado del comportamiento del mercado de trabajo en Estados Unidos y, por el otro, de la existencia de una tradición muy arraigada del migrante mexicano de regresar a su país en épocas navideñas.

Lo anterior es un acontecimiento muy significativo, pues de acuerdo con la información obtenida, de las entrevistas realizadas en Tijuana, ${ }^{13} \mathrm{de}$ los migrantes que han tenido experiencia migratoria el $96 \%$ declaró que siempre ha cruzado por esta ciudad.

Tijuana es una ciudad que enmarca una larga tradición migratoria por su vecindad con California, uno de los estados más ricos de la Unión Americana; en este estado

...se concentra en cualquier época más del $50 \%$ del volumen total de migrantes indocumentados mexicanos, a pesar de la distancia que hace de Tijuana la ciudad fronteriza más lejana de las regiones desde donde tradicionalmente proviene la migración hacia Estados Unidos (Bustamante, 1987: 22).

La temporalidad y la estancia del migrante indocumentado en la ciudad de Tijuana son dos fases del proceso migratorio que repercuten directamente en el ámbito económico y social de la ciudad; por un lado existe una derrama económica debido al acceso a servicios que requieren los migrantes y, por otro, es una población que generará una mayor demanda en los

${ }^{12}$ El Colegio de la Frontera Norte realiza el proyecto denominado "Cañón Zapata", el cual tiene curno objetivo principal realizar un monitoreo de los flujos de migrantes indocumentados hacia la frontera norte. Dicho proyecto tiene dos objetivos específicos; primero, se pretende conocer las variaciones del flujo migratorio a través de folografias tornadas de uns manera sistemática en tiempo y espacio desde agosto de 1986 a la fecha, en el lugar que fue durante varias decadas el cruce tradicional de migrantes indocumentados que emigran hacia Estados Unidos. El segundo objetivo específico es conocer las características socioeconónicas del migrante indocumentado en el momento del cruce: para lograr lo anterior se aplica un cuestionario conto a una muestra seleccionada al azar durante tres días cada semana, este procedimiento se realiza desde agosto de 1987 a la fecha, las ciudades donde se administran estos cuestionarios son: Tijuana, Mexicali, Cd. Juárez, Nuevo Laredo y Matamoros.

${ }^{13}$ De octubre de 1987 a enero de 1990 se realizaron 7,844 entrevistas en la ciudad de Tijuana, y de esta población 3,076 ha tenido experiencia migratoria, el 95\% corresponde a esta última cantidad. 
servicios en determinadas épocas del año, principalmente en los meses de junio, julio y agosto.

El migrante indocumentado se ve "obligado" a permanecer por un tiempo determinado en Tijuana, ${ }^{14}$ dependiendo de su éxito o fracaso para cruzar hacia Estados Unidos, ya que cuando es deportado hará un nuevo intento de cruzar la frontera.

\section{Infraestructura de servicios existente}

\section{Oferta hotelera}

Este rubro ha sido de los que han presentado un crecimiento más dinámico dentro de los servicios y hacia donde se han dirigido importantes financiamientos del sector público, principalmente a través de créditos otorgados por el Fondo Nacional de Fomento al Turismo (FONATUR). ${ }^{15}$

En sólo tres años (1985-1988), la oferta de establecimientos de alojamiento turístico, que comprende los hoteles de 1 a 5 estrellas, experimentó un crecimiento del orden del $272 \%$, y en términos de cuartos del $117.2 \%$. De 1988 a 1989, el número de establecimientos permaneció casi constante, pero no así la oferta de cuartos, que registró una disminución del $27 \%$. Tijuana cuenta con aproximadamente el 53\% de la oferta hotelera distribuida como se muestra en el cuadro 2 .

A pesar de que Tijuana no es un destino turístico de playa, ni cuenta con grandes atractivos naturales o arqueológicos, se encuentra en séptimo lugar a nivel nacional en lo que se refiere a oferta hotelera. En términos de ocupación también se encuentra entre los más altos, después de Hermosillo, Ciudad Juárez y Guadalajara, con el 66\% (SECTUR, 1989: 167-168). Algo interesante de señalar es que la gran mayoría de los visitantes extranjeros no pernoctan en la ciudad, lo cual nos dice que la mayoría de sus visitantes son nacionales, ya que es una importante plaza financiera, comercial e industrial, además de que la vecindad con California permite acceder a otro tipo de atractivos.

\footnotetext{
14 Un cálculo aproximado sobre el número de migrantes que presentan estas características de temporalidad fue realizado por Rodolfo Corona (1986:27), quien señala "Suponiendo que cada migrante temporal permanece en Baja California 15 días, entonces la cantidad de migrantes masculinos temporales en ese estado durante 1980, con edades de 15 a 35 años, se encontraba entre 1'080,887 y 1'536,699 individuos" es importante considerar estas estimaciones, dado que Tijuana es la ciudad de mayor cruce de migrantes indocumentados, y ello repercute tanto en el ámbito económico como social.

${ }^{15}$ Organismo creado para apoyar la inversión turística.
} 
CUADRO 2. Oferta de establecimientos de hospedaje en Tijuana, 1989.

\begin{tabular}{lrrrrrr}
\hline & \multicolumn{2}{c}{$1985^{*}$} & \multicolumn{2}{c}{$1988 * *$} & \multicolumn{2}{c}{$1989 * *$} \\
Categoría & Est. & Hab. & Est. & Hab. & Est. & Hab. \\
\hline 5 estrellas & 1 & 430 & 1 & 429 & 1 & 429 \\
4 estrellas & 4 & 604 & 7 & 869 & 6 & 812 \\
3 estrellas & 3 & 275 & 25 & 1339 & 22 & 1213 \\
2 estrellas & 13 & 685 & 28 & 1104 & 26 & 944 \\
1 estrella & 4 & 163 & 32 & 943 & 30 & 828 \\
Suites & & & 3 & 215 & 3 & 78 \\
Clase económica & & & 72 & 1810 & 69 & 1779 \\
Apartamentos & & & 6 & 160 & 9 & 232 \\
Cuartos & & & & & 1 & 12 \\
Sin categoría & & & & & 9 & 299 \\
Totales & 25 & 2157 & 174 & 6869 & 176 & 6626 \\
\hline
\end{tabular}

FUENTE: * Secretaría de Turismo del Estado.

** Delegación Federal de Turismo en el Estado.

\section{Oferta restaurantera}

En cien afios el número de restaurantes existentes en Tijuana ha crecido de 3 establecimientos que había en 1889 a 1,024 que existían en $1989 .^{16}$ Según la Cámara Nacional de la Industria Restaurantera y Alimentos Condimentados (CANIRAC) "la oferta restaurantera beneficia directamente [por el empleo que genera] a más de 20 mil familias, e indirectamente a una cifra mayor".

En 1989 existían en Tijuana 96 restaurantes de calidad turística, ${ }^{18}$ con una cobertura diaria de 192,060 asientos lo que se traduce en una potencial oferta mensual de atención a 5'838,624 comensales. ${ }^{19}$ Los de categoría turística están orientados tanto para la población nacional como extranjera, de

16 "Otorgó el cabildo de México, la primer licencia para vender comida y bebidas". Declaraciones del C.P. Óscar Escobedo, Presidente de CANIRAC, durante 1989 (ABC, 11 de julio de 1989).

17 "La industria restaurantera entre los principales atractivos turísticos" (El mexicano, 1o. de marzo de 1989).

${ }_{18}$ La calidad turística de los restaurantes depende de los servicios adicionales que ofrece el restaurante; como por ejemplo si tiene estacionamiento, si aceptan tarjetas de crédito, si cuenta con personal bilingüe, entre otros. Esto es independiente de la localización y el tipo de comida que ofrecen.

19 "CANIRAC informa". Secc. turismo (El Mexicano, edición estatal del 25 al 31 de mayo de 1988). 
tal suerte que es uno de los principales atractivos de la ciudad, por lo menos así se infiere en términos de su participación en la distribución del gasto.

\section{Transporte aéreo}

El Aeropuerto Internacional de Tijuana recibe diariamente a miles de visitantes en sus líneas comerciales. En 1986 recibió 825 mil personas, de las cuales casi el 100\% llegaron en vuelos nacionales. Para 1987 se registró un considerable descenso del $23 \%$, que coincidió con el decremento en la oferta de asientos disponibles. Esta disminución registrada en 1987 a nivel nacional, afectó la demanda de vuelos, como consecuencia del incremento de las tarifas aéreas atribuible a la baja del ingreso real de la población. Según los índices de precios del Banco de México el importe por transporte aéreo se incrementó en $152.3 \%$ en 1986, y en 179.2\% en 1987; esto explica, en buena medida, que algunos usuarios se hayan visto en la necesidad de buscar otras alternativas de transporte y un medio más económico para desplazarse (SECTUR, 1989:223).

De 1987 a 1988 la captación de pasajeros fue del orden del 12\%, esto pese a que la frecuencia de vuelos y los asientos disponibles disminuyeron en un 23.2 y $20.5 \%$, respectivamente. En 1989 se incrementó la recepción de viajeros, la mayoría proveniente de vuelos nacionales, asimismo, se incrementó en 34\% la oferta de asientos. A nivel nacional Tijuana representa la tercer plaza más importante de vuelos nacionales, en lo que se refiere a flujo de pasajeros, sólo superada por México y Guadalajara (SECTUR, 1989:264; véase cuadro 3).

CUADRO 3. Llegada de pasajeros, frecuencia y asientos disponibles en vuelos nacionales $\mathrm{e}$ internacionales al aeropuerto de Tijuana (comercial A).

\begin{tabular}{lccrcc}
\hline Año & Total & Frecuencias & $\begin{array}{c}\text { Asientos } \\
\text { disponibles }\end{array}$ & $\begin{array}{c}\text { Vuelos } \\
\text { nacionales }\end{array}$ & $\begin{array}{c}\text { Vuelos } \\
\text { internacionales }\end{array}$ \\
\hline 1985 & 825090 & 6300 & 985500 & 824730 & 360 \\
1986 & 895040 & 7600 & 1248000 & 881160 & 13880 \\
1987 & 689180 & 6900 & 1106600 & 683220 & 5950 \\
1988 & 774060 & 5300 & 879500 & 772970 & 1090 \\
1989 & 990790 & 6700 & 1179200 & 989300 & 1490 \\
\hline
\end{tabular}

FUENTE: Tomado de Estadísticas básicas de la actividad turística, SECTUR, 1989; Aeropuerto y servicios auxiliares. 
Tijuana es un punto prioritario de cruce dentro de la trayectoria migratoria hacia Estados Unidos; por lo tanto, los vuelos hacia esta ciudad en periodos vacacionales no satisfacen la demanda de viajeros; por esta razón a partir de 1990 se inició la ampliación del aeropuerto, con la idea de ofrecer un mejor servicio a sus usuarios. ${ }^{20}$

Tijuana no ha escapado de la crisis económica; sin embargo, ha experimentado un acelerado crecimiento económico durante los últimos años, propiciando mejores condiciones de bienestar y empleo en relación al resto del país, esto ha permitido que sea un factor de atracción para los visitantes de negocios.

\section{TIPOLOGÍA DE LOS VISITANTES QUE HACEN USO DE SERVICIOS EN TIJUANA}

El estudio de la población flotante demanda la necesidad de recurrir a diversas fuentes de información complementarias que puedan proporcionar un mayor conocimiento del tema, identificando indicadores comunes que ayuden a comprender sus características. ${ }^{21}$

Entre los principales visitantes detectados se encuentran: los turistas extranjeros (anglosajones, mexicano-norteamericanos, europeos y asiáticos) los migrantes (temporales, interestatales e internacionales entre estos últimos distinguimos a documentados e indocumentados), el turismo nacional, el visitante por negocio, y el que solamente viene a hacer uso de servicios (ya sea nacional o extranjero). Para efectos de este trabajo solamente se hará referencia al turista anglosajón, mexicano-norteamericano y nacional, al migrante indocumentado, que se le denominará "visitante itinerante", y al visitante nacional.

Cuando hacemos referencia al turista que visita Tijuana, se señala al turismo fronterizo extranjero que día a día arriba a la ciudad en busca de satisfactores, sin considerar relevante el tiempo de duración de su visita, ni la distancia del recorrido. ${ }^{22}$ Una persona será turista mientras haga uso de su tiempo libre en actividades propias del turismo, como son: la diversión, el

${ }^{20}$ Como un dato adicional, cabe señalar que la frecuencia de vuelos en aviones DC10 a ciudades tan pequeñas como Zacatecas y Aguascalientes se debe principalmente a que en estas ciudades, se cubre la capacidad de los mismos por la demanda tanto de migrantes documentados e indocumentados que van hacia Estados Unidos.

21 El motivo de visita a familiares y amigos detectado en los perfiles del turista, y el alojamiento en el caso de algunos migrantes declarando familiares y amigos, puede ser también detectado en las encuestas socio-demográficas en su característica de no residentes-temporalmente presentes.

22 Para abundar en el tema Cfr. Nora L. Bringas "Definición conceptual de turismo fronterizo" ( inédito). 
descanso y aquéllas que tienen que ver con la búsqueda del desarrollo personal a través de la cultura y las artes. Con esta definición se pretende señalar que no se considerará a los migrantes como turistas, a pesar de que son usuarios de servicios que tradicionalmente se han considerado como turísticos, como es el caso de los hoteles, restaurantes, y diferentes servicios de transporte.

Al momento de planear la diversificación de la oferta de servicios es importante tener presente que los migrantes son un grupo específico de población, que generalmente se les ha concebido como una carga social en lo económico, omitiéndose que son una fuente importante de ingresos que contribuyen a la economía de la localidad. En cambio, la población que viene por motivos de negocios tienen entre sus actividades combinar el trabajo con el descanso y la diversión ejerciendo una demanda importante en los servicios turísticos.

\section{Perfil del visitante nacional}

El renglón de los visitantes nacionales ha sido de los más descuidados en la planeación de servicios, principalmente en la actividad turística; generalmente cuando se habla del turismo se asocia el término con personas provenientes del extranjero y se tiende a olvidar que los propios nacionales también son parte del mismo.

Un indicador que muestra la poca atención que se le ha brindado al turismo nacional es la escasa información de datos estadísticos acerca de la afluencia y el perfil de este visitante. La única información existente al respecto, se refiere al estado de Baja California y data de $1987 .^{23}$

Las estadísticas sobre ocupación hotelera muestran que en 1989 se hospedaron en los distintos establecimientos de la ciudad, poco más de un millón de visitantes nacionales (ver cuadro 4). Como se aprecia en la figura 1, Baja California aparece como uno de los estados con mayor demanda de hospedaje por parte del visitante nacional.

El perfil del visitante nacional al estado ${ }^{24}$ muestra que el gasto promedio por persona fue de aproximadamente 70 dólares, ${ }^{25}$ del cual

\footnotetext{
${ }^{23}$ Por lo que a la afluencia de visitantes respecta, tampoco se cuenta con información. Para suplir esta ausencia, se considera el número de personas del país hospedados en los distintos hoteles de la ciudad, aunque con esta medida se está subestimando la afluencia real de nacionales; a falta de otros datos tomaremos como válidos los de ocupación hotelera (SECTURE, 1987).

24 Toda la información que se proporcione sobre el perfil del visitante nacional a Baja California fue tomada de "El perfil estatal del visitante nacional" elaborado por la Secretaría de Turismo del Estado en 1987.

25 El gasto promedio se refiere por visita; se hizo la conversión a dólares a un tipo de cambio de 1,500 m.n. que en 1987 regía el mercado cambiario; en realidad el gasto promedio fue de $\$ 104,517.00 \mathrm{~m} \cdot \mathrm{n}$.
} 
CUADRO 4. Oferta hotelera y ocupación en Tijuana.

\begin{tabular}{ccc}
\hline Año & Núm. de cuartos & Ocupación \\
\hline 1985 & 4674 & 59.1 \\
1986 & 4917 & 63.2 \\
1987 & 4706 & 62.3 \\
1988 & 4704 & 64.9 \\
1989 & 4742 & 66.0 \\
\hline
\end{tabular}

FUENTE: Estadísticas básicas de la actividad turística, 1989. SECTUR.

el $54.8 \%$ fue destinado a manutención y hospedaje (26.7 y $28.1 \%$, respectivamente); $13.4 \%$ a gasolina, $8.3 \%$ a consumo de bares; $8 \%$ a diversiones y el $5.5 \%$ restante a otros servicios.

La información referente a los visitantes nacionales señala que el $46 \%$ proviene del estado de Baja California, ${ }^{26}$ el $11.7 \%$ de Sonora, el $7.3 \%$ del Distrito Federal, el 5.7\% de Jalisco, el 3.7\% de Baja Califomia Sur y el 25.6\% restante de otros estados de la república. La estancia promedio de estos visitantes es de dos días tres horas, lo cual resulta significativamente mayor a los extranjeros que en ese mismo año fue de 16 horas. $^{27}$

Entre los principales motivos señalados por los visitantes sobresalen las visitas a familiares y amigos (32.21\%), por lo que es muy posible que no hagan uso de servicios hoteleros y por ello se incrementa la subestimación de las corrientes nacionales hacia la entidad; como segundo propósito de la visita a la ciudad aparecen aquéllos que tienen que ver con la realización de negocios (21.94\%); un porcentaje más bajo, $17.86 \%$, señaló que venía a divertirse y el resto viene de compras, a las playas, a eventos deportivos o por cuestiones de salud.

\section{Perfil del visitante itinerante}

Haremos referencia a los migrantes indocumentados como visitantes itinerantes; bajo esta categoría se denominará a las personas que vienen del interior del país ${ }^{28}$ a Tijuana con el objetivo de cruzar a Estados Unidos de

\footnotetext{
${ }^{26}$ Estos datos muestran que existe un gran porcentaje de visitantes intraestatales.

27 El tiempo de la visita es un dato importante para la planeación de actividades y servicios que pueden ser ofrecidos a estos visitantes.

${ }_{2}$ Tijuana es una ciudad en la que confluyen migrantes de varios estados del país tales como Distrito Federal, Jalisco, Sonora, Sinaloa, Michoacán, Oaxaca, Guanajuato entre otras. Para más detalles ver Ofelia Woo Morales (1990).
} 
manera indocumentada. Por lo que se considera a este visitante como actual y potencial usuario de la infraestructura de servicios (principalmente de hoteles y restaurantes), pues sin ser turista se ve en la necesidad de utilizarlos.

La potencialidad del visitante itinerante como usuario de los servicios consiste en relacionar diferentes factores entre los que destacan los siguientes: a) el comportamiento del flujo migratorio; b) permanencia del migrante indocumentado en Tijuana; c) temporalidad del migrante en Estados Unidos; y d) estancia en la ciudad de Tijuana.

Se han realizado algunos estudios donde se sefala que el flujo migratorio tiene un comportamiento estacional que se incrementa en verano, principalmente durante los meses de junio, julio y agosto y desciende en octubre, noviembre y diciembre; lo anterior está relacionado con las necesidades del mercado laboral en Estados Unidos y, por otra parte, con la tradición de los migrantes de regresar a su lugar de origen en épocas navideñas (Bustamante, 1987). Esta situación provoca que en determinadas temporadas Tijuana tenga una alta concentración de migrantes que aspiran a cruzar de manera ilegal a Estados Unidos.

Las formas de cruce hacia dicho país y la permanencia del migrante en la ciudad se ven determinadas por factores que no dependen de la voluntad del migrante; por ejemplo, los niveles de vigilancia de la patrulla fronteriza y el éxito o fracaso en el momento de cruzar hacia Estados Unidos. Sobre esto es importante señalar que el Servicio de Inmigración y Naturalización de Estados Unidos, a través de la patrulla fronteriza, ha aumentado el equipo de vigilancia (principalmente en la frontera Tijuana-San Diego), el cual ha sido concentrado en la zona de "el bordo". A mediano plazo, esto podría ser un indicador de una mayor dificultad para el cruce de los migrantes como indocumentados.

Existe una fuerte demanda por parte de los migrantes indocumentados hacia el tipo de infraestructura que pueda "satisfacer" sus necesidades durante su permanencia en la ciudad antes de emigrar, como son los servicios que prestan algunos hoteles con tarifas especiales para esta población (los clasificados en clase económica), además de los restaurantes y bares que se han convertido en principales puntos de reunión tanto para migrantes y agentes de cruce (coyotes o polleros).

Como se aprecia en el cuadro 5, el $22 \%$ de los migrantes indocumentados que cruzan por Tijuana registra una estancia de $3 \mathrm{a} 7$ días, y en el periodo de uno a siete días se observa un porcentaje acumulado de $86.1 \%$. Para estos migrantes, la permanencia en la ciudad antes de emigrar a Estados Unidos requiere de la realización de determinados gastos, principalmente en alimentación y hospedaje, pues su estancia promedio en Tijuana es de 2.1 días. 


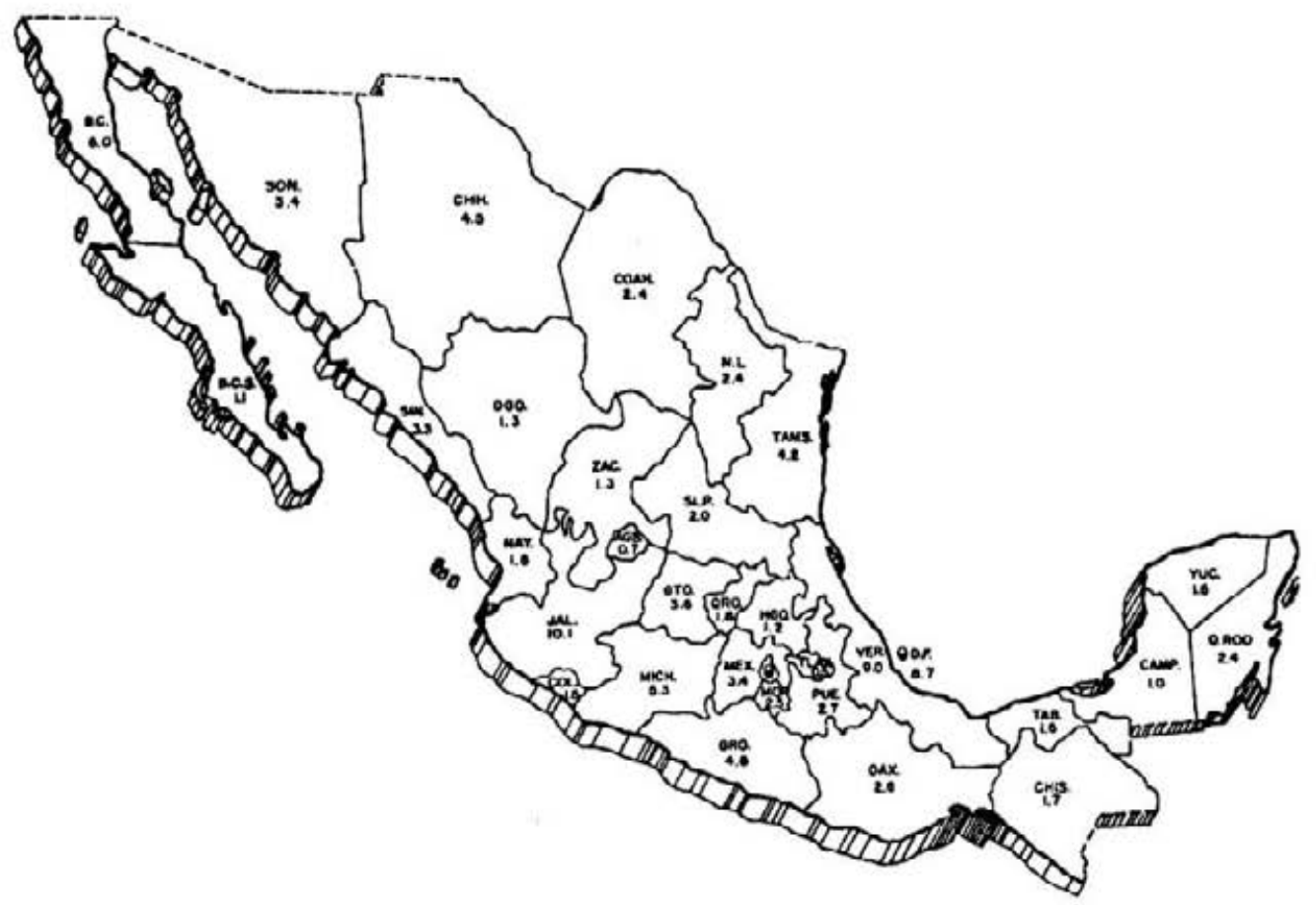

FIGURA 1. Distribución porcentual de turismo nacional que demanda alojamiento hotelero dentro del territorio nacional. FUENTE: Estadisticas básicas de la actividad turistica (SECTUR, 1989). 
CUADRO 5. Permanencia del migrante indocumentado en Tijuana.

\begin{tabular}{lc}
\hline Número de días & Porcentaje \\
\hline Llegó hoy & 45.9 \\
Llegó ayer & 18.1 \\
De 3 a 7 días & 22.1 \\
De 8 a 15 días & 5.8 \\
De 16 a 29 días & 0.7 \\
Un mes & 2.1 \\
Dos meses & 1.0 \\
De 3 a 6 meses & .9 \\
No especifica & 3.5 \\
Total & 100.0 \\
\hline
\end{tabular}

FUENTE: Proyecto “Cañón Zapata”, agosto de 1987 a enero de 1990, Tijuana, Baja Califomia.. COLEF.

La temporalidad del migrante indocumentado en Estados Unidos es un factor importante en su proceso migratorio, ya que repercute tanto en la economía del migrante, como en la ciudad por donde cruzan. Algunos estudios sobre migración indocumentada mencionan que el migrante va a trabajar a Estados Unidos por periodos cíclicos (por tres o seis meses) con el deseo de regresar a su país. Según Díez-Canedo (1984)

la mayoría de los migrantes internacionales a los Estados Unidos se proponen trabajar una temporada, ahorrar y volverse a su tierra. Los mexicanos [...] pueden volverse a su país de manera relativamente fácil y, por esa razón, han mantenido las mismas características ocupacionales a lo largo de su historia migratoria.

El carácter temporal del proceso migratorio implica repercusiones económicas en la ciudad fronteriza de cruce hacia Estados Unidos, ya que más del $90 \%$ de los migrantes que han tenido experiencia migratoria cruzan por la misma ciudad. ${ }^{29}$

Los principales gastos que realiza el visitante itinerante durante su trayectoria migratoria hacia Estados Unidos son: transporte (de su lugar de origen al lugar de cruce), hospedaje, alimentación y pago al coyote, gastando un promedio de 228,000 pesos en 1988 y 270,000

${ }^{29}$ Este porcentaje se refiere a los migrantes entrevistados en Tijuana en el momento de cruce hacia Estados Unidos en el proyecto "Cañón Zapata", 1987-1990, El Colegio de la Frontera Norte. 
en 1989; los rubros que representan una mayor derrama económica directa para la ciudad de Tijuana son hospedaje y alimentación, pero también producen una derrama indirecta a través del pago a "coyotes" y el servicio de transporte.

En el cuadro 6 se observa que el porcentaje más alto de los migrantes indocumentados que fueron entrevistados en Tijuana pernoctaron en un hotel; $y$ en segundo y tercer lugar en importancia fueron con familiares y amigos respectivamente ${ }^{30}$ de lo anterior se infiere que aproximadamente el $70 \%{ }^{31}$ tiene que realizar gastos mínimos de alimentación, lo cual forma parte del costo del proceso migratorio.

\section{CUADRO 6. Alojamiento de los migrantes indocumentados en} Tijuana.

\begin{tabular}{lrrr}
\hline Porcentaje & 1987 & 1988 & 1989 \\
\hline Familiares & 8.2 & 12.4 & 11.9 \\
Amigos & 7.1 & 5.8 & 6.3 \\
Hotel & 49.3 & 36.2 & 24.0 \\
Autobús & 10.9 & 16.3 & 22.0 \\
Detenido (por la patrulla & & & \\
fronteriza) & 2.1 & 2.4 & 8.8 \\
Otros* & 22.4 & 26.9 & 27.7 \\
Total & 100.0 & 100.0 & 100.0 \\
& & & \\
\hline
\end{tabular}

FUENTE: Proyecto "Cañón Zapata". COLEF.

* Corresponde a diferentes reactivos que no llegan al $7 \%$.

El gasto promedio de los migrantes durante su estancia en la ciudad de Tijuana es de 116,500 pesos, que representa aproximadamente el $50 \%$ del gasto promedio total, cantidad que significa un costo de migración muy elevado si se relaciona con el salario mínimo en México.

\footnotetext{
${ }^{30}$ Es importante señalar que existen fuentes de información que pueden ayudar a una mayor comprensión del estudio de la población flotante, se puede recurrir, por ejemplo, a las encuestas sociodemográficas del estado de Baja California (CONEPO, 1986), a las encuestas de migrantes indocumentados como la Encuesta en la frontera norte de trabajadores indocumentados devueltos por las autoridades de los Estados Unidos de América, diciembre de 1984 (ETIDEU), Estadísticas básicas de la actividad turística (SECTURE, varios años), Perfil del visitante nacional y extranjero (SBCTURE, 1987).

${ }^{31}$ Sumando los tres rubros principales, hotel, familiares y amigos en 1987,1988 y 1989.
} 
De lo anterior se destaca que los visitantes itinerantes representan una derrama económica importante dentro de los servicios de la actividad turística no cuantificada, y que consiste en los gastos que realizan en la ciudad, como son: el transporte (taxi) que utilizan desde su llegada a la ciudad (central de autobuses) hasta la línea fronteriza o lugar de cruce, y el pago al coyote o pollero para que los introduzca a Estados Unidos.

\section{Perfil del visitante residente en el extranjero: de origen mexicano y anglosajón}

En Tijuana, como en el resto del estado, cuando se habla de turismo extranjero generalmente se piensa en los visitantes anglosajones, aun cuando existen estudios que señalan la importante participación de la población de ascendencia mexicana en la composición de los grupos de visitantes, lo cual se ha incrementado con miles de connacionales que legalizaron su estancia en el vecino país.

El perfil del visitante extranjero está compuesto en un $57 \%$ de población de origen mexicano, un $28.7 \%$ de anglosajones y el $14 \%$ restante de negros, asiáticos, latinos y europeos. ${ }^{32}$ Se sabe que la mayoría de estas personas provenían de los condados de San Diego y Los Ángeles principalmente. ${ }^{33}$

La permanencia de los visitantes extranjeros en las ciudades fronterizas, generalmente se reduce a pocas horas; el $46.1 \%$ de mexicanonortcamericanos y $\mathrm{cl} 48.3 \%$ de los anglos permanecen hasta 4 horas, $y$ cl $28.7 \%$ y el $30.5 \%$ respectivamente, permanecen entre 5 y 8 horas. En general, el $81.3 \%$ de los mexicoamericanos y el $82.6 \%$ de los anglos se queda hasta doce horas en la ciudad; el $13.5 \%$ de los mexicano-norteamericanos, y el $12.4 \%$ de los anglos permanece de uno a dos días; el 5.1 y el $5.3 \%$ respectivamente, más de dos días.

Otro aspecto importante para nuestro análisis, se refiere al gasto que realizan los visitantes extranjeros, donde observamos que el gasto promedio de los mexicoamericanos es de aproximadamente 37 dólares y el de los anglos es de 42.2; estas diferencias podrían asociarse a los motivos del viaje, pues el de los mexicano-norteamericanos es principalmente para visitar familiares y amigos (46.4\%) y en ocasiones no realizan compras o gastos; mientras que los anglosajones manifestaron como principal propósito

\footnotetext{
32 "Investigación estadistica del turismo fronterizo $\mathrm{r}$ ", (COLEP, 1987). Esta información consta de 1,462 cuestionarios que se levantaron en la línea intemacional de San Ysidro, durante 17 días de septiembre y octubre de 1987. Véase también Nora Bringas (1990).

${ }^{33}$ De acuerdo con la fuente del cuadro anterior el $42.4 \%$ de los anglos y el $69.6 \%$ de los mexicoamericanos que procedían de San Diego y de Ios Ángeles, el $18.1 \%$ de los mexicoamericanos y 12.62 de los anglos.
} 
de sus visitas, realizar compras (36\%). Las diferencias en el gasto pueden derivarse de que el nivel de ingresos del primer grupo está por debajo del que tienen los anglos, aunque también puede ser que lo bajo del ingreso los obligue a buscar servicios más baratos (mecánicos, médicos, farmacias, entre otros).

La distribución del gasto se presenta de acuerdo con los siguientes rubros: en el caso de los anglos, más de la tercera parte de su gasto lo destinaron a comprar artesanías (34.5\%); el $17.2 \%$ a comer en restaurantes; el $10.1 \%$ a comprar ropa; y un $9.5 \%$ en diversión, y el restante $28.7 \%$ se destina a hoteles, abarrotes y a la utilización de diversos servicios, principalmente médicos. Por otra parte, el principal gasto para los mexicanonorteamericanos fue en servicios, que comprende desde mecánicos u hojalateros, hasta dentistas y médicos $(29.6 \%)$; además, el $14.3 \%$ es invertido en abarrotes, $7.4 \%$ en curiosidades; y un $7 \%$ en diversión; $11.1 \%$ en restaurantes y el $30.6 \%$ restante en ropa, hotel, farmacias, medicinas, y materiales para la construcción. ${ }^{34}$

\section{ORIENTACIÓN DE LA INFRAESTRUCTURA DE SERVICIOS}

La avenida Revolución es una de las principales arterias turísticas de la ciudad. ${ }^{35}$ En esta avenida se concentra una gran proporción de restaurantes, terrazas-bar, centros nocturnos, tiendas de curiosidades, de artesanías y de importación. Por ella pasean miles de visitantes extranjeros; por las mañanas se puede ver desfilar a personas en compañía de sus familiares y/o amigos en busca de algún artículo típico o de la famosa "mexican food", bebiendo una margarita, comprando su perfume favorito o, simplemente, tomando un recuerdo fotográfico: retratándose en una carreta con un burro pintado de cebra y ataviado con motivos mexicanos.

Por las noches, la avenida Revolución cambia su fisonomf́a y se orienta hacia un turismo preponderantemente joven. Diariamente, pero con mayor intensidad los fines de semana, en esta avenida se dan cita miles de jóvenes que buscan divertirse en las numerosas terrazas-bar, discotecas y centros noctumos.

La mayoría de los restaurantes utilizados por los visitantes anglosajones se encuentran localizados en la avenida Revolución; mientras que el

\footnotetext{
34 Lo anterior muestra el apoyo del turismo en otros sectores de la economía local.

35 La avenida atraviesa perpendicularmente once calles, inicia en la Avenida Internacional, pegado a la línea divisoria en la zona conocida como "el bordo" —esta zona es desde 1988 a la fecha, el lugar de mayor concentración de migrantes indocumentados que pretenden cruzar hacia Estados Unidos-, tres cuadras antes de la calle primera, y llega hasta la calle once, cambiando su nombre por Boulevard Agua Caliente.
} 
grupo de visitantes que proviene del interior del país, acude principalmente a los restaurantes ubicados a lo largo del Boulevard Agua Caliente y en la Zona del Río; el grupo de visitantes "itinerantes" hace uso de los pequeños restaurantes existentes en la zona norte de la ciudad y; finalmente, el grupo de mexicoamericanos utiliza en forma más variada los restaurantes ubicados en distintos puntos, debido a la mayor movilidad que presentean en comparación con el turista anglosajón, facilitada por el uso del idioma español, así como por gustos culinarios.

La población nacional es la principal usuaria de servicios de hospedaje, tal como se aprecia en el cuadro 1. En 1989, el 79\% de la población hospedada en hoteles fueron nacionales, contra $21 \%$ de extranjeros. En los últimos quince años, más de las dos terceras partes de los cuartos de hotel ocupados han sido demandados por turistas nacionales. Esto resulta obvio, si se tiene presente nuestro señalamiento con relación a la corta estancia que tienen los turistas extranjeros, quienes generalmente no pernoctan en la ciudad.

Los visitantes itinerantes (migrantes indocumentados) hacen uso de hoteles clasificados como "categoría económica" y "una estrella". En 1989, estas categorías conformaban el $39.3 \%$ de la oferta de cuartos, aunque en términos de establecimientos es mayor y representó el $56 \%$ de la oferta. ${ }^{36}$

La mayoría de los hoteles de clase económica se encuentran localizados en las zonas norte y centro de la ciudad, ubicada cerca del "bordo", principal área de cruce de migrantes indocumentados, quienes demandan, de manera importante, dichos servicios. La densidad por habitación en estos hoteles es más alta que la de los hoteles de categoría turística; sin embargo, el precio estimado por persona es más bajo. ${ }^{37}$

\footnotetext{
${ }^{36}$ Los precios que se han establecido para la clasificación de hoteles son: 45,000 clase económica; 60,000 una estrella; 90,000 dos; 150,000 para tres estrellas; 210,000 cuatro estrellas; y 310,500 pesos, cinco estrellas. El procedimiento para verificar que se respeten los mismos es a través de las instancias arriba señaladas con verificaciones e inspecciones ordinarias. Todos los hoteles, independientemente de quien los demande, tienen asignados precios por categoría que son regulados y sancionados por la Delegación Federal de Turismo y la Procuraduría Federal del Consumidor.

37 Para determinar los hoteles de clase económica que habitualmente utiliza el visitante itinerante se realizó el siguiente procedimiento: Primero se detectaron los hoteles de categoría económica, sin categoría y apartamentos que sumaban un total de 76 , de éstos sólo se recabó información telefónica de los que se localizan en la zona centro y norte de la ciudad, por ser éstas las más frecuentadas por los migrantes indocumentados. Se identificaron 63 hoteles en estas zonas, de los cuales 38 dieron información, 16 se negaron y los teléfonos de los 9 restantes, no correspondían con los proporcionados por la SECTURE. Los hoteles sin categoría y los apartamentos no están regulados por la SECTURE, por lo cual de la información obtenida sólo se consideran los 33 casos que corresponden a hoteles de categoría económica.
} 
Como se deduce en el cuadro 7 , independientemente de los precios establecidos, el $43.1 \%$ del total de hoteles acepta dos personas por habitación, el $4.6 \%$ tres; el $18.5 \%$ hasta cuatro; el $23.1 \%$ no tiene restricciones en cuanto al máximo de personas y, el restante $10.8 \%$ no se encontraba especificado. ${ }^{38}$

\section{CUADRO 7. Rangos de tarifas y número de personas permitidas por habitación}

\begin{tabular}{lrrrrr}
\hline Rangos de precios & \multicolumn{5}{c}{$\begin{array}{c}\text { Porcentaje de hoteles según el número de } \\
\text { personas permitidas por habitación }\end{array}$} \\
& 2 & 3 & 4 & Sin límite & N.E.* \\
\hline & 4.6 & & 1.5 & 1.5 & \\
$0-25,000$ & 13.8 & & 1.5 & & 3.1 \\
$26,000-35,000$ & 9.2 & 4.6 & 3.1 & 4.6 & 3.1 \\
$36,000-45,000$ & 7.7 & & & 4.6 & \\
$46,000-55,000$ & & & & & \\
$56,000-65,000$ & & & 12.3 & 7.7 & 3.1 \\
$66,000-75,000$ & 7.7 & & & 4.6 & 1.5 \\
$75,000-$ más & & 3 & 12 & 15 & 7 \\
Total = 65 & 28 & 3 & & & \\
\hline
\end{tabular}

FUENTE: Investigación directa.

NOTA: El tipo de cambio en dólar era de $\$ 2,978.00$ pesos m.n.

$*$ N.E. $=$ No especificado.

En cambio, los hoteles de las categorías de 2 a 5 estrellas conforman el $51.3 \%$ de la infraestructura de cuartos, y el $31.3 \%$ de establecimientos; con excepción de los ubicados en la avenida Revolución que son utilizados por extranjeros, el resto (que se encuentran en diferentes puntos de la ciudad), son utilizados por el turismo nacional (véase cuadro 2).

\section{IMPORTANCIA ECONÓMICA DEL TURISMO Y LA MIGRACIÓN}

La generación de divisas por concepto de turismo resulta de significativa importancia para el desarrollo de la ciudad; para ilustrar este punto

${ }^{38} \mathrm{El}$ precio estimado por persona es más bajo porque se incrementa el número de personas aceptadas por habitación. En los casos estudiados, los rangos de precios por habitación están dentro del precio oficial; sin embargo, el servicio que se ofrece es mínimo, y el hacinamiento por habitación es muy alto. Independientemente de las personas que son aceptadas por habitación el $24.6 \%$ de los casos están dentro de un rango que va de 36,000 a 45,000 y el $30.8 \%$ está entre el rango 66,000 y 75,000 moneda nacional. 
basta mencionar que en 1987 se hospedaron en los distintos hoteles de la ciudad 1'055,500 visitantes nacionales (SECTUR, 1989). Si multiplicamos el gasto promedio per cápita por el número de turistas hospedados en ese año, se tiene que la derrama económica generada fue de poco más de 73.8 millones de dólares (véase cuadro 8).

En ese mismo año ingresaron a Tijuana aproximadamente 590 millones de dólares por concepto de turismo extranjero, el cual tuvo un gasto promedio per cápita de 44 dólares, menor al realizado por el visitante nacional, que fue de 70 dólares, aunque el volumen del primer grupo estuvo por encima del último ${ }^{39}$ (véase cuadro 8 ).

De 1987 a 1988 aumentaron los ingresos turísticos en aproximadamente $80 \%$, - a pesar de que la estancia promedio disminuyó de 16 horas en 1987, a 13 en 1988 197-, lo cual se derivó del aumento en el número de turistas y del incremento en el gasto promedio por visitantes de 44 a 53 dólares. ${ }^{4}$

En 1988, el perfil del turista extranjero mostró que el gasto promedio por visitante fue de aproximadamente 53 dólares y el número de visitantes a Tijuana en ese mismo afio fue de 20.1 esto significa que ingresaron a Tijuana 1,059.8 millones de dólares por concepto de turismo.

Otro elemento importante en la derrama económica de la población flotante que llega a Tijuana es el de los visitantes "itinerantes" o migrantes indocumentados. Uno de los aspectos más relevantes que tiene el proceso migratorio como efecto económico directo en las ciudades de cruce es la temporalidad, permanencia o recurrencia del mismo.

39 Estas grandes diferencias entre la derrama económica generada por el visitante nacional y el extranjero se debe, por una parte, a imprecisiones en la elaboración de estadísticas oficiales y, por otra, a que el volumen de la corriente de visitantes extranjeros es muy superior a la de los nacionales.

40 Pefil del turista extranjero (SECTURB, 1984-1988).

${ }^{41}$ Se debe aclarar que Tijuana es la puerta de entrada para visitantes que se desplazan a Rosarito, corredor turístico y Ensenada. Por lo que al momento de considerar la derrama generada en Tijuana se tiene que ponderar esa cifra, en este caso se trata de aproximarse un poco más a lo que realmente aporta el turismo económicamente a la ciudad; para ello, del total de cruces registrados por la puerta de Tijuana se excluyó el porcentaje correspondiente de visitantes extranjeros que en el perfil del turista extranjero que elabora la SECTURE, manifestaron como destino final la ciudad de Tijuana; el problema es que hasta la fecha no se cuenta con la información precisa por lo que debemos ser cautelosos al manejar este renglón. Además, la SECTURB considera cada cruce como si fuera un visitante o turista, lo cual no es así, dado que cada vez que pasa una persona al vecino país se registra como un cruce, y si esta persona cruza dos veces se contabiliza como si se tratara de un visitante más, motivo por el cual no se puede confiar en esta cifra para hacer referencia a los visitantes (SECTURE, 1988). 
CUADRO 8. Derrama económica estimada de los visitantes en la ciudad de Tijuana (1987-1988).

\begin{tabular}{lcccrrr}
\hline $\begin{array}{l}\text { Tipo de } \\
\text { visitantes }\end{array}$ & $\begin{array}{c}\text { Núm.de } \\
\text { visitantes }\end{array}$ & $\begin{array}{c}\mathbf{1 9 8 7} \\
\text { Gasto } \\
\text { promedio } \\
\text { (dls.) }\end{array}$ & $\begin{array}{c}\text { Gasto } \\
\text { total } \\
\text { (dls.) }\end{array}$ & $\begin{array}{c}\text { Núm.de } \\
\text { visitantes }\end{array}$ & $\begin{array}{r}\text { 1988 } \\
\text { Gasto } \\
\text { promedio } \\
\text { (dls.) }\end{array}$ & $\begin{array}{r}\text { Gasto } \\
\text { total } \\
\text { (dls.) }\end{array}$ \\
\hline Itinerante & 119068 & $106.7^{\mathrm{b}}$ & 12704555 & $91397^{\mathrm{b}}$ & $100.0^{\mathrm{a}}$ & 9139700 \\
Nacional & 1055500 & $70.0^{\mathrm{a}}$ & 73885000 & 1144000 & $70.0^{\mathrm{c}}$ & 80080000 \\
$\begin{array}{l}\text { Extranjero } \\
\text { Total }\end{array}$ & $13363840^{\mathrm{d}}$ & 44.1 & 589746000 & $20129860^{\mathrm{d}}$ & 52.6 & 1059830000 \\
& & & 664048517 & 140209500
\end{tabular}

FUENTE: Elaboración propia con base en información de: Itinerante: Proyecto "Cañón Zapata", CoLEF, 1987-1988; Nacional: Pefil del visitantenacional, SECTURE, 1987; Extranjero: Servicio de Inmigración y Naturalización de los Estados Unidos y Perfil del visitante extranjero, SECTURE, 1987- 1988.

NOTA: ${ }^{a} \mathrm{El}$ gasto promedio estaba en moneda nacional y se convirtió a dólares a un tipo de cambio para 1987 de $\$ 1,500$ y $\$ 2,279$ para 1988.

"En estas cantidades no se incluye a quienes cruzaron por "el bordo" tanto para el año de 1987 como de 1988.

${ }^{c}$ Por no existir información para este año, se consideró el mismo gasto que el año anterior.

¿Esta información se obtuvo del total de cruces que se registraron en Tijuana; y sólo considera para 1987, el 67.3\% del total de cruces que según datos de la SECTURE declararon como destino final Tijuana, y para 1988 fue el $84.3 \%$ del total. 
La mayor afluencia de los visitantes itinerantes se registra en los meses de junio, julio y agosto y se reduce drásticamente en octubre, noviembre y diciembre; cste factor es importante considerarlo ya que son los meses en que se va a incremantar o disminuir la demanda de servicios en la ciudad, la temporalidad se convierte en un factor importante para la planeación de los servicios demandados por esta población.

Los migrantes tienen estrategias de cruce que se van adecuando en el trayecto de su ruta migratoria. Como fue señalado anteriormente, Tijuana está considerada como una ciudad importante en cl cruce migratorio; de aquéllos que han tenido experiencia migratoria más del $90 \%$ declaró que cruza por la misma ciudad; esto aunado con que el proceso migratorio es recurrente, ya que implica una derrama económica significativa para la ciudad, pues es una población que emigra hacia Estados Unidos sólo por temporadas y regresa a su lugar de origen y, en ocasiones, este proceso se realiza generacionalmente.

Si bien, las estimaciones que presentamos aquí pueden estar sobrestimadas; lo que nos interesa rescatar en este documento es la importancia que puede significar la participación económica de los visitantes itinerantes o migrantes internacionales, los cuales contribuyen en la economía local. En 1987 su gasto total erogado fue aproximadamente de 119,068 mil dólares, ${ }^{42}$ que si bien no es muy grande en comparación con el registrado por los extranjeros, sí resulta significativo, y no corresponde a la creencia común de que los migrantes se consideran una carga para la ciudad.

\section{CONCLUSIONES}

El desarrollo de la actividad turística en Tijuana ha estado sujeto a los vaivenes de la economía estadounidense, dependiendo de los momentos de auge o recesión económica del vecino país. Tijuana tiene una potencialidad efectiva para atraer corrientes turísticas dada su colindancia con el principal emisor de turismo mundial que es Estados Unidos. Esta potencialidad no se ha aprovechado, posiblemente como consecuencia de campanas promocionales mal orientadas, o porque no se dispone de una oferta variada de servicios, pues únicamente se prevén las necesidades de los jóvenes anglosajones, por lo que la iniciativa privada invierte en las áreas y sitios más frecuentados por este tipo de visitantes.

\footnotetext{
42 Es necesario señalar aquí que sólo estamos contabilizando a la población que se concentró en 1987 y 1988 solamente en el lugar denominado "Cañón Zapata", y no se consideró otro punto importante de concentración que es "el bordo".
} 
Generalmente, al turismo nacional no se le da la importancia que merece pese a que es el principal usuario de hoteles y restaurantes en la ciudad, además de que su estancia es mayor que la del turista extranjero. Al "visitante itinerante", por su parte, se le brinda menor atención, principalmente porque no dispone de recursos económicos suficientes para hacer uso de servicios de mejor calidad y, aunque son considerados como una carga para la sociedad receptora, poco se sabe sobre su contribución a la economía local.

Existe otro tipo de población que consideramos debería de ser estudiado más detalladamente, es el migrante que se legalizó en Estados Unidos con la ley Simpson-Rodino, cambiando su condición de migrante indocumentado (o visitante itinerante) a turista (o como comúnmente se le llama "el regreso del paisano" o "rodino", demandando servicios a los que antes no podían acceder.

En la medida que la crisis económica por la que está pasando México no logre superarse, y dado que la migración de indocumentados tiende a incrementarse, es posible pensar que las ciudades de la frontera como Tijuana, continuarán recibiendo estos visitantes temporales, que demandarán servicios y generarán una derrama económica importante, por lo que se requiere realizar estudios tendientes a diagnosticar sus necesidades como parte del proceso de planeación y desarrollo de la ciudad.

Es necesario conocer los diferentes visitantes y los servicios que demandan para realizar una mejor planeación de los recursos y orientarlos hacia áreas y servicios poco atendidos, tratanto de lograr la integración del sector.

Tijuana es, y en el mediano plazo seguirá siendo, una ciudad con un gran dinamismo así como un punto de atracción de diferentes modalidades de visitantes; es por cllo que se deben de establecer planes y estrategias para un mejor desarrollo de la oferta de servicios, orientada a satisfacer la heterogénea demanda de sus futuros visitantes.

\section{BIBLIOGRAFÍA}

ACEVEDO, Conrado. et al. 1985. "Semblanza de Tijuana 1915-1930". Hisloria de Tijuana. Semblanza general. Instituto de Investigaciones Históricas. UNAM-UABC. Tijuana.

BUSTAMANTE, Jorge A. 1987. "La migración de los indocumentados". El cotidiano, no. especial 1.

- 1990. Historia de la colonia Libertad. El Colegio de la Frontera Norte. Tijuana. 
BUSTAMANTE, Jorge y Wayne Cornelius (compiladores). 1989. Flujos migratorios mexicanos hacia Estados Unidos. Ed. Comisión sobre el futuro de las relaciones México-Estados Unidos y Fondo de Cultura Económica.

BRINGAS, Nora L. 1990. "Turismo fronterizo: características de los visitantes de origen mexicano y angloamericano en Tijuana". Ponencia presentada en Association of Borderland Scholars. 21 al 24 de febrero de 1990 . Tijuana, B.C.

- $\quad$ s/f. "Definición conceptual de turismo fronterizo" (inédito).

COLEF. 1986. Encuesta demografica de Baja California.

- 1987-1990. "Cañon Zapata" proyecto.

- 1987. "Investigación estadística del turismo fronterizo 1".

CONEPO. 1986. Encuesta sociodemográfica del estado de Baja California. 1989. Encuesta continua de población, B. C.

CORONA, Rodolfo. 1986. Medición indirecta de la inmigración temporal en Baja California. Aportes de Investigación/2. Centro Regional de Investigaciones Multidisciplinarias. UNAM. México.

- 1991. Principales caracteristicas demográficas de la zona fronteriza del norte de México. COLEF.

DIEEZ-CANEDO, Juan. 1984. La migración indocumentada de México a los Estados Unidos. Un nuevo enfoque. Fondo de Cultura Económica. México.

ESTRELLA, Gabriel. 1987. "Ni son todos los que están, ni están todos los que son". Ponencia presentada en el Simposio binacional sobre población en la frontera, Tijuana, B.C., del 8 al 11 de junio de 1987. SDSU COLEF.

INEGI. 1983. X censo general de polación y vivienda.

KÜSEL, Corina. s/f. "Tijuana: ¿Una ciudad donde fluyen leche y miel? Desarrollo de la economía y de las condiciones de reproducción". En: Víctor Klagsbrunn.

MUNGARAY, Alejandro L. 1985. “Actividades económicas”. En: David Piñera, et al. "Inicio de Tijuana como asentamiento urbano". Historia de Tijuana. Semblanza general. Instituto de Investigaciones Históricas. UNAM-UABC. Tijuana.

PIÑERA, David. et al. 1985. "Inicio de Tijuana como asentamiento urbano". Historia de Tijuana. Semblanza general. Instituto de Investigaciones Históricas. UNAM-UABC. Tijuana.

- " "Panorama de Tijuana 1930-1948". Historia de Tijuana. Semblanza general. Instituto de Investigaciones Históricas. UNAM-UABC. Tijuana. 
SECTUR. 1989. Estadisticas básicas de la actividad turística, 1987-junio de 1988. México.

SECTURE. 1984, 1985, 1986, 1987 y 1988. Perfil del turista extranjero, 1987. Perfil estatal del visitante nacional.

WOO MORALES, Ofelia. 1990. "La defensa de los derechos humanos en la investigación académica: la experiencia de los migrantes en una región fronteriza Tijuana-San Diego". Ponencia presentada en el II Seminario, la Universidad y los derechos humanos en América Latina. Universidad Iberoamericana. México, D.F. 6 al 9 de noviembre de 1990.

\section{Priódicos}

$A B C$. "Otorgó el cabildo de México la primer licencia para vender comida y bebida". 11 de junio de 1989.

El Mexicano. "La industria restaurantera entre los principales atractivos turísticos". 1ro. de marzo de 1989.

- $\quad$ "CANIRAC informa". Edición estatal del 25 al 31 de 1988. 